(C2020. This manuscript version is made available under the CC-BY-NC-ND 4.0 license http:// creativecommons.org/licenses/by-nc-nd/4.0/

\title{
Tackling fuel poverty through household advice and support: exploring the impacts of a charity-led project in a disadvantaged city in the United Kingdom
}

Sam Ramsden

Energy \& Environment Institute, University of Hull, Cottingham Rd, Hull HU6 7RX, Hull, UK

\begin{abstract}
This article explores the impacts of a charity project which aimed to help people vulnerable to fuel poverty improve their energy efficiency and reduce energy costs, through providing energy monitors and advice at a household-level. The research makes an important contribution to emerging but scarce research on how charities can help households vulnerable to fuel poverty. Interviews were conducted with 40 participants and 32 participants described how the project helped them (through one or a combination of the following): reduce inefficient energy use; switch tariffs; change from pre-payment meters; apply for subsidies for vulnerable people; and/ or improve their confidence to manage their household energy needs. Nineteen of the participants were vulnerable to fuel poverty and fifteen of these estimated that the project helped them save money. While achieving financial savings was the key motivation for participants, 15 households described that they participated in the project to reduce their $\mathrm{CO}_{2}$ emissions. However, the approach was limited and the impacts could have been increased through energy audits, property-level energy efficiency improvements, and support to raise issues with housing providers. The research argues that household-level face-to-face advice and support can help people vulnerable to fuel poverty and charities can operate effectively in a space between the government, energy companies, local authorities and households to provide this support. However, charities need access to technical expertise, reflexive funding, and effective coordination with local authorities to improve their long-term impact.
\end{abstract}

\section{Introduction}

Fuel poverty is a persistent issue in the UK which affects approximately $11 \%$ of households $[1,2]$. Fuel poverty is driven by energy inefficient housing, low incomes, and high fuel prices and causes financial, health and social consequences for vulnerable people [3-6]. There are a growing number of community and household-level projects which aim to help people vulnerable to fuel poverty [7], but there is a need for more research to explore their impacts [8,9].

This article explores the approach, impacts and long-term sustainability of a charity-led energy feedback and advice project that worked with low-income households in Kingston-upon-Hull (more commonly known as Hull), in the north of England. Hull is an economically-disadvantaged city and at the time of the research in 2015 , approximately $14 \%$ of households lived in fuel poverty, and this had increased from 11\% in 2011 [10]. The project focused on reducing energy usage and costs for households vulnerable to fuel poverty. The project worked at a householdlevel and provided an energy monitor to review the use of electricity, provided advice on energy 
tariffs, and discussed the Warm Home Discount (WHD) - a UK Government scheme which provides an annual $£ 140$ discount off energy bills for eligible low-income people. Through this approach the charity aimed to improve the skills and confidence of householders to manage their energy usage and costs. The article includes accounts from project participants to illustrate findings, before contextualising the case study findings and making recommendations to support policy and practice.

This article therefore adds to an emerging and important area of energy research by presenting empirical data on the outcomes and challenges of a charity-led household energy project working directly with vulnerable people $[8,9,11]$. The article explores this project as a case study to add to our understanding of whether projects that focus on household-level advice and energy feedback can help people who are vulnerable to fuel poverty, the potential role of charities in this work and whether this work should be supported.

\section{Literature review: exploring interventions that can help households vulnerable to fuel poverty}

Sovacool [6] describes that 'affordability matters from an energy policy perspective - when energy prices rise and households cannot afford heat or electricity, it is functionally the same as if they lack access to reliable energy services altogether'. While definitions of fuel poverty are complex, fuel poverty is driven by energy inefficient housing, low incomes, and rising fuel prices [4,6,12]. Fuel poverty particularly affects vulnerable people including older people, people with disabilities, and people on low incomes [3-6]. Liddell and Morris [13] identify that a large percentage of fuel poor people live in houses that are cold and damp, damaging health and causing excess winter deaths. Fuel poverty is a form of energy injustice which is underpinned by distributional injustice, procedural injustice and lack of recognition [4-6]. Distributional injustice is identified as the unequal distribution of energy services [4]. Procedural injustice affects whether households are able to make informed energy decisions, including the choice of suppliers and tariffs, and the use of pre-payment meters, and is influenced by a lack of transparent information [4]. Both Walker and Day [4] and Snell et al. [5] identify that vulnerable people suffer from a further injustice in that decision makers are not recognising the needs of vulnerable groups, and there is little participation from vulnerable groups in decision making. These issues also affect the ability and confidence of vulnerable people to challenge energy justice issues. As an example of how energy justice issues influence fuel poverty, Snell et al. [5] describe a relationship between pre-payment meters and fuel poverty. Many vulnerable people have to use pre-payment meters due to difficulties paying bills and falling into debt with suppliers, or have moved into properties, particularly rental properties, with existing pre-payment meters. Pre-payment meters require payment or 'topping up' before energy use and it is estimated that nearly 6 million people have pre-payment meters in the UK [14]. Pre-payment meters have higher tariff rates, there are fewer options to switch to more competitive deals and it is difficult to change payment method from pre-payment meters to direct debit. In addition, supplies can be cut-off if users run out of credit.

There are many projects aiming to help people vulnerable to fuel poverty, operating at different scales, including improving the energy efficiency of housing stock, providing cheaper energy from 
local and renewable energy sources including solar panels, and providing help and advice to vulnerable people to improve their energy efficiency $[1,7-9,15]$. This article focuses on projects that provide help and advice at a household-level. Reeves [8] researches 12 community projects that provided household-level interventions, including energy audits, property-level energy efficiency improvements, energy monitors, advice on tariffs and assistance applying for the WHD. The projects were operated by a range of actors including local authorities, professional organisations, charities and community groups. Many of the outcomes were described in terms of financial impacts and approximate savings per household per year from the activities included: helping households switch tariffs and suppliers ( $f 65)$; behaviour change to reduce energy usage (£130); and registering houses for the WHD (£140). Other benefits include households feeling warmer and less damp and participants having a greater understanding of links between energy efficiency and health outcomes. Lorenc et al. [16] researched a charity project that helped households vulnerable to fuel poverty reduce fuel costs by helping them switch energy suppliers and describe that from the 151 people included in the research, 19 tried to switch tariffs of which 13 were successful and 'anticipated savings were between $£ 20$ and $£ 150$ a year', with these savings broadly in line with the findings of Reeves [8].

Baker et al. [9] describe the outcomes of a household-level energy advice and advocacy project provided by a community-based organisation to help people vulnerable to fuel poverty. Baker et al. [9] feature accounts from 11 project beneficiaries who described a wide range of outcomes including more efficient use of appliances, installation of more energy efficient appliances such as lights and heating systems, home improvements such as draft proofing, switching to cheaper tariffs, and help applying for the WHD. There was direct help to resolve energy issues with suppliers such as obtaining help to fix faulty meters, but there was also evidence of increasing people's capability and confidence to manage household bills more effectively. Participants were reluctant to estimate financial savings, with the exception of one participant who estimated savings of $f 180$ per year. In conclusion, Baker et al. [9] make a strong argument to support projects that provide household-level face-to-face energy advice using trusted community intermediaries. Another important finding highlighted by both Reeves [8] and Baker et al. [9] is that projects find it very difficult to identify clearly who is in fuel poverty and therefore many projects work more widely at a community-level to reach people vulnerable to fuel poverty.

\subsection{Using energy monitors in reducing energy usage and costs}

Four of the 12 projects researched by Reeves [8] provided electricity monitors as part of their activities, to enable householders to review and reduce energy usage. Smart energy monitors can provide energy feedback through real-time information on energy usage and costs $[11,17,18]$. Pullinger et al. [18] state that aims of energy monitors are: 1) to develop a sustainable energy supply, by reducing domestic energy demand, reducing $\mathrm{CO}_{2}$ emmissions and increasing affordability and 2) to benefit householders through reducing energy bills and improving energy literacy. Hargreaves et al. [18] and Hargreaves et al. [20] present longitudinal qualitative research on the use of energy monitors by 15 householders and argue that the benefits of smart meters can include reducing consumption, improving information and confidence to manage usage and bills, and empowering people to raise issues with local authorities and institutions. 
However, from an environmental perspective Hargreaves et al. [18] describe that reductions in energy usage do not go beyond a 'certain level', resonating with arguments that energy feedback from smart meters has not led to large-scale changes in energy usage which are required to reduce energy consumption to sustainable levels $[11,17,19]$. For example, Strengers [17] states that the use of energy monitors 'potentially legitimizes practices that use energy resources, by focusing on what can be easily measured and saved, rather than what is considered normal and necessary'.

Since the longitudinal research by Hargreaves et al. [18] and Hargreaves et al. [20], the UK government has legislated that energy companies offer to provide smart meters to all homes in the UK by 2020 [21]. However, take-up by households is poor with reticence attributed to poor installation, poor customer service, inaccurate data and negative coverage in the media [21-24]. Wilson et al. [23] describe that the roll-out of smart meters could benefit from grants or technical advice 'to vulnerable households to support adoption of SHTs [Smart Home Technologies] for assisted living or for managing fuel poverty'.

Therefore, the literature identifies that energy advice and support at a household-level could be valuable to help households vulnerable to fuel poverty manage their energy usage more confidently and effectively [8,9], while also contributing to government policy [23]. However, more research is required to support these emerging arguments and to influence policy and practice. These issues will be examined through the case study of a charity-led household energy project working in a deprived area of the UK.

\section{Research context and methods}

The research was conducted in Hull in the Yorkshire and Humber Region of the United Kingdom, which has a population of approximately 260,000 [10]. Hull is an important historical city and there are many efforts to develop and showcase the city such as through the successful City of Culture 2017 bid and by working towards becoming the centre of the Renewable Energy Industry in the UK $[25,26]$. However, Hull is described as a structurally disadvantaged and declining maritime port city [26]. In 2015, at the time of the research, unemployment in Hull was $8.8 \%$ compared to a national average of 5.2\% [27], and Hull was also identified as the third most deprived Local Authority (LA) in England [28]. In 2015, the number of households in fuel poverty was $14 \%$, which was higher than the UK level of $11 \%$ [10]. Areas of north and east Hull have among the highest levels of fuel poverty in the city due to high levels of deprivation and due to large numbers of fuel inefficient council houses built in the inter-war and post-war periods.

The Green Prosperity (GP) project was the case study for the research and was a three-year project targeting deprived communities in east Hull from 2013 to 2015. The Green Prosperity project was a Communities Living Sustainably (CLS) project supported by the Big Lottery Fund (BLF). The BLF supported 12 CLS projects in deprived areas with goals to help vulnerable people, improve the environment and promote sustainable living, and up to $f 1 \mathrm{~m}$ in funding was provided for individual projects over a three to five year period [29]. The GP project was managed by a local charity and supported by two other local organisations and focused on two main activities: 1) Community Food 
Growing and 2) Household Energy Efficiency. This article explores the household energy project which aimed to support households reduce electricity use, through energy monitors, and help households access transparent information on tariffs and discounts for vulnerable people.

\subsection{Research methodology}

The research started in February 2014, one year after the GP project began, and continued until mid-2016 after the project completed. A key focus of the research was to understand the impacts of the household energy efficiency activity on participants. The research did not measure environmental impacts or conduct a cost-benefit analysis. The research aimed to use a mixed methods approach with a focus on semi-structured interviews to explore energy justice challenges faced by participants, supported by reviewing energy bills to identify reductions in energy usage and financial savings [9,30]. Participants were initially asked why they had become involved in the project and then if they had benefitted from the project's three main sources of help: 1) use of the energy monitor; 2) advice on tariffs including switching from pre-payment meters; and 3) information on the Warm Home Discount. Participants were then asked if they had saved any money and if it was possible to estimate savings either on a monthly or annual basis. The aim was to explore these benefits in more detail including whether the project helped participants address energy justice issues, such as fuel poverty, and explored whether participating in the project helped them achieve any environmental goals.

\subsubsection{Challenges encountered}

The author had a combined research and monitoring and evaluation (M\&E) role with the GP project, which was funded by the project and delivered in partnership with the University of Hull. The author was the only researcher involved in the project and there were issues relating to positionality which impacted on the research. For example, in trying to navigate a potential conflict between being an academic researcher and my M\&E role for the project, I aimed to be a 'critical friend' to provide valuable learning through a supportive approach [32,33], while also maintaining distance to avoid emotional attachment and avoid 'developing overly positive arguments' [34]. However, tensions in this balance crystallized towards the end of the project when staff wanted me to focus on collecting financial savings information to demonstrate impacts to help the project obtain further funding.

This meant in my combined role, I decided to try to reach as many participants as possible within a short period of time. However, it was very difficult to arrange interviews with residents who had only received one household visit and had no ongoing contact with project staff. On a practical level, many people gave mobile phone numbers which had since changed, and if contact was made many people did not want to give up time to answer questions due to other priorities such as providing care or working. If contact was made by telephone or email I often felt under pressure to ask questions there and then rather than try to arrange a face to face interview at a later date. However, on the positive side, the project management team did not put pressure on me to push respondents into estimating savings they were not comfortable with. This period also highlighted the realities of working on a charity-led project that was due to have its funding stopped. 
There were also other issues that impacted on the methodology. Even though I aimed to use a mixed methods approach to identify financial savings and reductions in $\mathrm{CO}_{2}$ emissions, I did not ask for copies of electricity bills as evidence, as ongoing project work had shown that participants were very reluctant to share this information and pushing people to share energy bills could have put participation at risk, resonating with research by Baker et al. [9], Gupta et al. [14] and Hargreaves et al. [18]. In addition, it was very uncomfortable asking people if they felt they lived in fuel poverty, particularly in phone interviews where I found it difficult to establish any trust or rapport, and I only asked this question directly on four occasions during face-to-face interviews with participants who indicated they had financial challenges.

\subsubsection{Interviews with participants}

By the end of the research, 40 participants were interviewed, representing $8 \%$ of the 475 people that had received energy monitors. It is important to note that these 40 participants are not the only participants to benefit from the project, but are the ones who engaged in the research. For instance another 35 respondents reported that they made savings directly to the project staff but I was unable to follow-up with these participants. The interviews were conducted in three phases: summer 2014, spring 2015 and autumn 2015, mainly between 1 and 2 years after participants received the home visit, advice and energy monitor. However, two interviews were conducted shortly after the project intervention due to accessibility although these two participants did not estimate any savings from the energy monitor, with one only describing savings from an immediate tariff switch.

Face-to-face interviews were conducted with 13 households which lasted between 20 and 30 minutes, of which 12 were recorded and transcribed. In general, it was only possible to conduct face-to-face interviews with the project's ongoing participants: 10 were conducted with participants who were also involved in the project's food growing activities; and two were participants from a sheltered housing scheme where interviews were arranged through the GP project and the Housing Warden. The 27 other respondents were contacted through the project database, with 10 of these suggested by the GP staff member as being willing to be interviewed. Twenty-four householders were interviewed by phone and three households chose to communicate by email. Phone interviews lasted between 10 and 30 minutes but were not recorded as I did not want to add another barrier to participation, Only one householder contacted 'cold' through the database agreed to a face-to-face interview. The household characteristics of those interviewed are shown in Table 1 below.

Table 1: Household Characteristics of Interviewees

\begin{tabular}{|l|l|l|l|l|}
\hline Gender & Female -24 & Male -13 & Couples -3 & \\
\hline Age & 65 and over -13 & 45 to $54-13$ & 25 to $44-14$ & \\
\hline Property type & Terrace -22 & $\begin{array}{l}\text { Semi-detached }- \\
6\end{array}$ & Flat -5 & Bungalow -4 \\
\hline
\end{tabular}




\begin{tabular}{|l|l|l|l|l|}
\hline Tenancy & $\begin{array}{l}\text { Local Authority } \\
(\mathrm{LA})-12\end{array}$ & $\begin{array}{l}\text { Sheltered } \\
\text { Housing }-4\end{array}$ & $\begin{array}{l}\text { Registered Social } \\
\text { Landlord (RSL)_- } \\
2\end{array}$ & $\begin{array}{l}\text { Other }{ }^{1}-22 \text { (of } \\
\text { which 6 ex-LA } \\
\text { properties) }\end{array}$ \\
\hline Other & $\begin{array}{l}\text { Family }-11 \text { (of } \\
\text { which 3 single } \\
\text { parents) }\end{array}$ & $\begin{array}{l}\text { Long term sick } \\
\text { and disabled - } \\
14\end{array}$ & $\begin{array}{l}\text { Pre-payment } \\
\text { meters - 5 }\end{array}$ & \\
\hline
\end{tabular}

Coding of interview notes and transcriptions was conducted on an ongoing basis to feedback information to the project as part of monitoring and evaluation activities. Codes were developed from the main themes discussed during the interview including motivations of joining the project, benefits and discussions of energy justice issues. In addition, themes brought-up by interviewees were also analysed, for example a number of participants described how they used the monitor to identify inefficient electrical appliances, whereas other participants described difficulties in using the energy monitor.

\subsubsection{Research with wider stakeholders}

Interviews were conducted with GP staff including the project lead and the household energy activity manager. A range of local project stakeholders were also interviewed including: housing wardens from the sheltered housing scheme and a Registered Social Landlords (RSL) working with the project; and the affordable warmth, financial inclusion and climate change leads from Hull City Council (HCC). In addition I attended two Affordable Warmth Strategy working group meetings led by the council which brought together stakeholders from HCC (including housing, health, and climate change), representatives of RSLs and charities including the Citizens Advice Bureau. I also attended a national CLS workshop facilitated by the Energy Saving Trust to bring together learning from the projects. Twelve participants of the project's food growing activities were also asked why they hadn't participated in the household energy project.

In conclusion, the research was fairly simple in its approach and there were challenges in the methodology. Energy research expertise brought in at the beginning of the project could have developed a more rigorous and effective approach [30], such as by joining the household visits during the first year to set-up data collection and follow-up research interviews. In addition, it could also be argued that the research could have been more independent from the project. However, the research was conducted with an active project and I was able to access a relatively large number of research participants, many of whom were vulnerable to fuel poverty, as well as meeting with a wide range of stakeholders and participate in wider stakeholder activities. The participants interviewed provide essential perspectives on energy justice issues and how the project helped them. In addition the research was conducted during the project activities and after the activities had been completed, allowing the research to explore successes, challenges and to track long-term sustainability. The following section explores the research findings in detail.

\section{Findings: Examining the household energy project and its impact on low-income groups}

\footnotetext{
${ }^{1}$ We did not ask if people were renting from private landlords. Most of these respondents were owneroccupiers. Very few private tenants engaged with the energy activity.
} 
This section explores the GP project's household energy activity in five parts. The first part considers the approach of the charity to work with people vulnerable to fuel poverty. The second part describes how people benefitted from the project activities, before part three focuses on the experiences of participants vulnerable to fuel poverty in more detail. Part four reviews whether participants considered that their involvement in the project helped them achieve environmental objectives and the fifth part considers long-term sustainability. The findings include direct quotes from participants and pseudonyms have been used to protect anonymity.

\subsection{Approach to working with people vulnerable to fuel poverty}

The project focused on household-level interventions and provided energy monitors to local residents as a practical way of reducing costs, with a secondary aim to reduce carbon emissions. The GP project aimed to install 500 energy monitors in the target areas of east Hull and used Owl Micro Monitors which had a large display with the monitor showing real-time increases in electricity usage when appliances are used. The project also used the household visit to provide information on tariffs, discuss the use of pre-payment meters, and provide information on the Warm Home Discount (WHD). The project prioritised messages on reducing costs as this was viewed as being particularly important due to levels of financial disadvantage and vulnerability to fuel poverty in the local community.

The project wanted to reach those in fuel poverty using the English Government's 'Low Income High Costs (LIHC) indicator where a household is considered to be fuel poor if: they have required fuel costs that are above average (the national median level) and were they to spend that amount, they would be left with a residual income below the official poverty line' [35]. However, the complexity of this definition meant that it was difficult to assess whether people were in fuel poverty, as it requires detailed information on personal finances, energy bills and energy efficiency which many householders will not analyse themselves and could be reticent to share this information with outside organisations $[16,18,36]$. In response, the project was open to working with any household within its target area to allow it to reach households vulnerable to fuel poverty. The project collected information on age, disability, sickness and employment to identify participants who were most vulnerable to fuel poverty and be able to report its impact in this area. The project also collected information on indicative savings from switching supplier or changing payment methods and whether the participant had been given information on the WHD. However, the level of information collected is in contrast to the detailed level of information collected by the projects researched by Baker et al. [9] which included: 'the number and age of household occupants; tenure; figures for electricity and gas costs, consumption before and after accessing support, and the resulting cost and $\mathrm{CO}_{2}$ savings; householder eligibility for different support options; details of actions taken - measures installed, debt written off, etc.; and in some cases details of household finances (income, debt)'. The relatively light touch on information requested reflected the difficulties in getting local residents to engage in the project, even though the service was free to users, and the project didn't want to put off potential participants with extensive demands for information. However, the project attempted to supplement this information with energy ratings and estimated energy costs collected by the council through a 
programme of household energy audits which were being conducted in the target areas, but information sharing was suspended due to data protection issues.

In terms of engagement, initially the charity strictly focused on residents in the target area of east Hull, but as the project developed it was flexible in reaching out to other households with the consent of BLF. The project initially contacted participants from a waste recycling survey it had conducted with approximately 1,000 residents, and 120 residents who completed the survey participated in the activity. The project then expanded methods of engagement to include leafletting, roadshows and attending community meetings in the target areas. Project staff also worked with Hull City Council (HCC) housing wardens and with other HCC and National Health Service (NHS) agencies operating in a local community hub - the Freedom Centre - to raise awareness. Staff also found it was able to engage more easily with people at home during the day and from October when the clocks changed and it became darker earlier, and people became more conscious of the energy they were using. By the end of the project in 2015, the 475 energy monitors were installed out of a target of 500 , with $71 \%$ going to residents in its target areas of east Hull, and $70 \%$ distributed to those it classified as 'vulnerable to fuel poverty'.

In addition to household-level work, the project worked closely with a sheltered housing provider Housing Warden to help engage residents and provide ongoing support - with the warden considered a 'trusted intermediary' [9]. Many of the sheltered housing tenants were older people who could be vulnerable to fuel poverty. The Housing Warden described how the energy monitor was considered a good way to engage people before providing advice on tariffs and the warm home discount:

'A lot of them [the tenants] don't understand, they just use the same supplier, and don't realise, and some just say "oh I'm alright with what I've got", so you've got to talk to them, so I think it would be real good to have the energy monitors.'

In contrast, long-term working relationships were not developed with other 'trusted intermediaries'. There was limited follow-up work with another RSL, after initial work with the housing warden to provide energy monitors to tenants, although potentially this was because the RSL was not based in east Hull. In addition, there was a limited approach to work with participants of the other strand of the GP project, the regular food growing participants, with only 10 of the approximately 50 regular participants having an energy monitor installed. Although a number of food growing participants were not interested, some expressed an interest but were not followed-up. In addition, there was no work with the more vulnerable food growing volunteers, such as those with mental health challenges.

In general, the project found it difficult to engage with specific groups of people: private renters who had short-term tenancies; people who had large families and didn't feel in control of costs; and more vulnerable people including people with mental health issues or with 'chaotic lifestyles' [9]. There was also very limited engagement with residents from ethnic minority backgrounds although there was a relatively small ethnic minority population in the target areas at the time of the research. 
A further restriction to its impacts was that the project did not expand its help to include detailed technical advice to improve energy efficiency such as by conducting an energy audit and identifying where household improvements could be made, or refer to other organisations that could support this work $[8,9]$. However, there were considerable barriers, some of which were not in the immediate control of the project: the activity was managed by one member of staff who did not have technical energy efficiency skills, although the staff member obtained an Energy Awareness National Vocational Qualification in 2015 to increase his knowledge. There was minimal technical support from BLF, and even though the Energy Saving Trust was involved in CLS at a national level, they did not visit the project or provide technical advice. In addition, although the project shared information with the local authority on its approach, and worked with operational staff to engage with local residents, there was no coordinated joint working approach under the direction of the Affordable Warmth Strategy group such as the LA asking the charity to focus on specific vulnerable people, or sharing information on the housing needs of vulnerable people which could then followed up by the council. Despite these limitations, the project reached a large number of people that could be vulnerable to fuel poverty and the benefits to participants are explored in more detail below.

\subsection{Examining whether participants benefitted from the project}

During the research, thirty-two of the 40 respondents interviewed identified they benefitted from the project, and 22 described they had saved money with estimated savings ranging from $£ 50$ to $£ 480$ per year, with average savings of $£ 171$ p.a. across the 22 households. These savings were achieved through using the energy monitor (17 households), advice on tariff changes (6 households), changing payment method from pre-payment meters to direct debit ( 2 households), with one household successfully applying for the Warm Home Discount (WHD) after advice. Four of the households numbered above saved money through a combination of using the energy monitor and advice on tariffs.

Using the energy monitor. Twenty-five households identified they had been able to use the energy monitor to reduce energy consumption with 17 of these saying they had achieved financial savings. The average estimated financial savings were $f 125$ p.a. across the 17 households, which is in line with the savings identified by Reeves [8] relating to behaviour change to reduce energy usage. Most respondents described how they used the energy monitor to keep an eye on usage and make small changes, such as switching off lights and closing doors to retain heat. However, the largest savings came from identifying and reducing the use of appliances with high energy use such as fluorescent lights, tumble dryers, and kettles, supporting arguments by Hargreaves [37]. For example, one resident had a second freezer in his garage with a broken thermostat. Placement of the energy monitor and visibility was very important, for instance, placing the energy monitor next to the TV. The following respondent describes how they used the energy monitor to increase the visibility of energy use and felt more in control and empowered, in line with the findings of Hargreaves et al. [18] and Hargreaves et al. [20].

'I think that's one of the greatest things about the monitor - you seem to be more in control or maybe the fact you can exactly see what energy your using each hour, it sort of 
empowers you....generally over the winter periods I would use both extra gas and electric. I found with the meter that my amount of electricity did not get any bigger at all, so I could easily say it was at least $£ 50$ a year saving I made, but also my normal monthly amount of electricity seems to last me a lot longer.' [Single parent respondent using pre-payment meter].

Five were using the energy monitor but were not ready to estimate savings. In addition, three respondents were unsure if they saved money, with two of these answering they were using the energy monitor but their partner takes responsibility for managing bills.

Fifteen of the 40 households were not using the energy monitor. Some had difficulties working the monitor, including describing that the batteries had run out, particularly participants aged 65 and over. In addition, one elderly couple also had a British Gas monitor and were confused by differences between the two monitors and wanted further advice. Two families with children identified it was difficult to change behaviour at a household level and control costs, with one of these families also describing how a family bereavement at the time of installing the energy monitor meant they had not engaged.

Advice on tariffs. Ten of the 40 respondents identified they benefitted from advice on their tariffs. Six identified how they saved money through negotiating better deals with existing suppliers or switching suppliers with average estimated savings of $£ 148$ across the six households. The average savings are higher than identified by Reeves [8] and Lorenc et al. [16], but only includes those who felt able to estimate savings. From the other four respondents, three said it helped them identify that their existing tariffs were competitive, and one changed supplier but were not ready to estimate savings. Two other respondents used the advice and information to move from pre-payment meters to direct debit, saving $£ 480$ and $f 120$. The resident who estimated they saved $£ 480$ a year took immediate steps to change payment method from pre-payment meter to direct debit for all their utilities after the face-to-face visit and information. However, the householder described how they needed to improve their credit rating which took a number of months.

These findings resonate with research on how advice and information can help people access better deals and improve confidence to manage household bills and deal with suppliers $[4,5,9]$.

Warm Home Discount. Three of the residents questioned had already obtained the WHD before contact from the GP project. One resident who cares for her disabled son was not aware of the WHD but after engaging with the project successfully obtained the discount of $f 140$. The project also provided a number of participants information on the WHD, but some residents reported significant difficulties obtaining information on the WHD from energy suppliers, and these issues are explored in more detail below.

\subsection{Exploring if the project helped people who were vulnerability to fuel poverty}

Twenty-three of the 40 participants interviewed were considered as vulnerable to fuel poverty including older people, people identifying as long-term sick and disabled, those caring for disabled relatives, people out of work, low income and high cost families, and people using pre-payment 
meters. Nineteen of these participants felt they had benefitted from the project and fifteen estimated they had saved money through the project: two through a combination of advice on tariffs and use of energy monitors; eight through using the energy monitor; two through tariff changes; two through changing from pre-payment meters to direct debit and one who received the WHD. In addition, two households were using the energy monitor but were not ready to say whether it had saved any money.

The stories of four households who were considered vulnerable to fuel poverty are highlighted below. The accounts illustrate some of the key energy justice issues people are facing and how participating in the project helped them. (Pseudonyms are used to protect anonymity and confidentiality).

Household 1: $\mathrm{Mr}$ and Mrs Franklin are a retired couple in their 70s who live in a sheltered housing scheme and could be considered vulnerable to fuel poverty as they described how they were not able to heat their home adequately:

Interviewer: 'Was it warm enough last winter?'

Mrs Franklin: 'It wasn't last winter when there was snow. That's when it's bitterly cold. You can have it on 6 which is the highest, but it is still cold. We've both got health issues so we are going to feel the cold.'

However, when asked if they considered themselves to be in fuel poverty, Mrs Franklin answered: 'No, we do pay direct debit monthly, it comes out every month so it's not that bad'. Mr and Mrs Franklin said they had now applied for the WHD with the support of the housing warden. They also described how they had placed the energy monitor next to the television in the kitchen to help them use it and had identified their fluorescent strip lights were energy inefficient. They were also planning to use the energy monitor to compare whether using the microwave or oven was more efficient. They also used the advice on tariffs to reduce their bills by approximately $£ 26 \mathrm{a}$ month:

'We went to EON from Npower, we're on a cheap one now but it wasn't, it was dear, got me fingers burnt.........we only went over on the 6th of November. But our direct debit has gone down from $£ 82$ and we're paying $£ 56$.'

Household 2: Barbara is a disabled grand-mother living on her own in a council house in east Hull. Barbara described how using the energy monitor had helped save her $£ 180$ per year mainly through reducing usage of an inefficient electric fire. '[I use the energy monitor] all the time, yes, because it surprises you, how much things cost... we use to use an electric fire all the time, but when you look at how much it costs.' Barbara did not consider herself to be in fuel poverty as she felt OK financially, however, saving money was becoming more of a concern as she was worried about a state benefits reassessment, and even though Barbara was told she will qualify for continued benefits, she was informed there could be a 4 to 8 week payment gap during the reassessment which would cause her significant financial difficulties. 
Household 3: Alison could also be considered as vulnerable to fuel poverty. Alison is a single parent, is unemployed and cares for her autistic son. Alison has financial challenges and describes how she uses foodbanks to help manage her household needs. She also lives in a council house and described how she had complained to the council about a draught coming through her front door, which had not been resolved at the time of research. However, Alison says she is not in fuel poverty as she has always managed to pay her bills: 'I haven't got into those kinds of difficulties because I have been careful to keep my energy bills down'. In the following quote Alison describes how she used the energy monitor and advice on tariffs to exert more control over her energy costs, although financial benefits were relatively small at approximately $£ 4$ a month:

'It's helped, and I've got my energy bills down... I was paying $f 72$ and I am now paying $f 68$ that's a month, that's just watching what uses the most energy and trying to reduce energy. ....I did get advice on Tariffs, but what I did was go to my own energy company and told them that I had been investigating other suppliers and they offered me a different tariff.'

Interviewer: 'Did that help reduce your bills?'

Alison: 'It probably did and they said that would bring the bills down [but] the thing that came through the bill most was watching my electricity use through the monitor.'

Household 4: Sarah could also be considered as vulnerable to fuel poverty. She lives in a fuel inefficient council house in east Hull with her family of four and both parents are in and out of work, and she also uses a pre-payment meter. However, when asked if she considered herself to live in fuel poverty she answered:

'No. I used to live in a very, very, cold, draughty house, freezing cold house, it was a big house as well.... since I moved out I've never had a cold house because I've had ice on the windows, freezing cold, so I won't let my kids, l'll go without to make sure the gas is paid when you've been there, you've been in that poverty you think I'll never do that again.....and I always keep the electric topped up.'

In the following quotation, Sarah explains how became engaged in the project and how she has used the energy monitor to reduce energy usage:

'Because we'd been to someone's house and it was like, you know, it's a new gadget isn't it, and they'd flick the kettle on and it would shoot right up, I said it's amazing, and she said if you go to GP and they'd come and fit it.. We did the thing where we switched everything off apart from the fridge and the freezer and we'd switch things on ......but it has been really good because it made me think, the tumble drier doesn't go on as much, when we first got it instead of putting it on we've got an airer, so we have two now, so everything goes in there.'

However, when she was asked if the project had helped her save any money, Sarah wasn't sure at that stage: 'I'm not quite sure really, because it's on a token meter [pre-payment meter] and it's all topped up, because I hate running out, and even though we might be using less, I still put the same amount in'. Sarah had also used involvement in the project as a platform to plan to 
move from pre-payment meter to direct debit, but described the difficulties she encountered: 'They just won't change it yet, some of them are really awkward....., we have to wait I think a year, when we switch suppliers, we wait a year and it's free, otherwise it will cost $£ 150$ - that's way too much.'

The stories indicate how all four participants benefitted from using the energy monitor, with the identification of inefficient appliances a key focus of their use: fluorescent light strips, an old electric fire and a tumble drier. The four participants also used advice on tariffs in a range of ways: to switch supplier, negotiate better tariffs with their own supplier, confirm their existing rates were competitive or as information as a platform to switch from pre-payment meter.

However, as well as highlighting benefits, the stories highlight a range of energy justice issues in relation to fuel poverty, including use of pre-payment meters, accessing the Warm Home Discount and improving energy efficiency in the home.

None of the four residents answered that they lived in fuel poverty, with a theme emerging that they did not consider themselves to be in fuel poverty as they were able to pay their bills, even if they had prioritised heating their home over other forms of essential expenditure. However, this highlights a problem in the complexity of the definition of fuel poverty used in England and could impact on vulnerable people being people being able to identify they are in fuel poverty and being able to access support.

Snell et al. [5] describe a link between pre-payment meters and fuel poverty [5] and Sarah's account illustrates the difficulties trying to move away from pre-payment meters. Another respondent described how he uses a pre-payment meter to manage his costs and keep in control of his finances:

'I don't pay electricity bills, or gas. I've got a key meter which is better for me as I don't pay bills. I refuse to use gas, because when I first moved in the house, I put $f 50$ pound on the electric and $f 50$ on the gas. I didn't use any gas, gone in two weeks......why? And they wouldn't tell me. I don't use no heating.'

Although some respondents felt using a pre-payment meter helps them control expenditure, the quote above also illustrates how lack of transparency on pre-payment meters stops people using energy, making them particularly vulnerable to fuel poverty [5]. Another respondent identified how using an energy monitor and advice from the project increased their awareness on the excessive charges for pre-payment meters, including using electricity at an emergency rate when there is less money in the meter:

'Electric meter, see how much it costs when it's at [Emergency Rate]. Ran out of money, running at higher rate, everything running at exactly the same but costing us more money. Wouldn't have known that if I hadn't have had the energy monitor on.'

In terms of the Warm Home Discount (WHD), only Barbara from the four featured respondents already received the discount, while Mr and Mrs Franklin had just applied with the help of the housing warden. The other two respondents had no plans to apply. Another resident of the 
sheltered housing described the barriers she encountered trying to help an elderly friend apply for the WHD.

Interviewer: 'Did you apply for a Warm Home Discount?'

Resident: 'Well I did for my friend [Morris] he's $92 \ldots$ and he's always cold, and oh what a palaver I had... well I rang the place, but not the supplier, I don't know, they give me this number to ring, and I rang it, and I haven't heard anything since and it must be a month ago... I thought I wouldn't bother with it myself because there's that much messing.'

The problems encountered by the resident featured above, together with the low number of project participants who had received the WHD, resonates with the findings of Walker and Day [4] and Snell et al. [5] on the lack of transparency of the grant system, the difficulties people experience in applying, and the lack of impact for vulnerable people.

A further energy justice issue described by two of the featured respondents was the need to make their houses more energy efficient. During the research, four respondents, including Alison, described receiving poor responses from the council to their requests to improve their energy efficiency and another respondent described receiving poor quality loft insulation work but was not clear who carried out the work. In addition, Mr and Mrs Franklin described living in a very cold flat within the sheltered housing project. However the project did include activities to improve energy efficiency at a property-level, raise issues with landlords, or refer specific cases to the local authority for follow-up.

In contrast to financial savings, there were no concrete findings into whether support from the project had helped improve participants' health and wellbeing - residents did not describe any benefits in this area. Although one participant identified how help with energy costs could help deal with a wider range of financial stresses including financial consequences of state benefits reassessments $[5,13]$. Conversely, residents did not describe that reducing energy consumption had affected their ability to heat their homes adequately - this had been raised as an area of concern by one stakeholder and would also be an important issue to follow-up.

\subsection{Exploring if the project achieved any environmental impacts}

Contributing to a reduction in $\mathrm{CO}_{2}$ emissions was a secondary aim of the project. The use of energy monitors by 25 of the 40 households to reduce energy consumption indicates some possible reduction in $\mathrm{CO}_{2}$ emissions. However, there was very limited evidence of reductions in $\mathrm{CO}_{2}$ emissions as householders were not asked to share utility bills, in line with the findings of Hargreaves et al. [18]. During the interviews, only one respondent stated that his primary motivation was to reduce his environmental impact:

'For me personally it is the wider environmental, because I do quite a lot with my job, I do quite a lot of environmental, so we come under lots of legislation, to be honest we are more easily bollocked if we mess up, to be honest money's not an issue it's just trying better things to do in all honesty, and this is another one isn't it really.' 
However, 15 of the 40 participants identified they were motivated by climate change and reducing their carbon footprint, and in some cases being involved in the project had increased their knowledge of climate change as an issue. Although, a number of these respondents also felt their own activities would not make a difference given the scale of the problem and the need for changes to be made at larger scales.

\subsection{Long-term sustainability}

The household energy efficiency activities finished after the Green Prosperity project funding stopped at the end of 2015. The lead charity applied for further funding to target new geographical areas and also approached other RSLs to work with their tenants. However, the project was unsuccessful in obtaining further funding, and project staff identified a major influence was government legislation for energy companies to provide smart meters by 2020 . At one stage, a council staff member suggested there could be a small amount of funding available for the charity to continue its work helping people vulnerable to fuel poverty. However, this was not part of the LA's Affordable Warmth Strategy discussions and this staff member left their position and no funding was provided.

Project continuation could also have allowed for follow-up and support with existing participants, such as helping people who had difficulties using energy monitors or assisting people to apply for the Warm Home Discount. However, the GP project felt it had exhausted working with residents who already had energy monitors. For instance, the energy monitor officer was not able to obtain any more savings information in 2016, including from people who had provided information before. In addition, staff also felt it had exhausted attempts to get other local residents from the two target wards to participate in the project. Some project stakeholders felt that expanding into renewable energy, especially providing solar panels, would benefit the local community, but the project lacked the technical skills and support to consider expanding to more technical energy interventions, in common with many charities leading community-level energy projects [8].

\section{Discussion}

\subsection{Summary of findings}

There were limitations to the research conducted as outlined in the methodology, including limited reach to project participants and limited time to interview some of the participants. However, there are valuable findings to consider in the development of approaches to help people who are vulnerable to fuel poverty. Working at a household-level, providing an energy monitor and helping people review tariffs, was a practical way to engage some participants. In addition, the charity did not try only to target those defined as in fuel poverty due to the complexity of the definition, which meant there were no barriers to participation. The project reached people vulnerable to fuel poverty and helped empower some participants to improve their confidence to manage their energy usage more effectively and reduce costs in line with research by Lorenc et al. [16], Reeves [8], and Baker et al. [9]. Thirty-two residents of the 40 participants interviewed said they benefitted from the project, with 22 identifying they had 
achieved financial savings. Estimated average savings were $£ 171$ p.a. across the 22 households. In comparison to the research of Reeves [8], the amount of savings achieved for project participants through using the monitor was similar but the savings achieved from tariff changes were higher. Nineteen residents who benefitted from the project were considered vulnerable to fuel poverty, with 15 of these achieving financial savings. Savings were achieved through reducing energy usage, mainly through reducing usage of inefficient appliances; and advice on tariffs which enabled people to switch suppliers or negotiate better rates with existing suppliers. Two residents used the project advice to move away from pre-payment meters, with another starting this process. One vulnerable resident became aware and successfully applied for the Warm Home Discount, with others starting the application process. These results show the value of household level support and advice to people who are vulnerable to fuel poverty.

However, there were limitations in the approach both from the charity and from supporting stakeholders. There was limited work with trusted community intermediaries who were close to vulnerable participants, such as housing wardens or the projects food growing staff, despite the benefits where this took place. In addition, the project found it difficult to engage some of the more hard-to-reach people in the community without this additional connection. There was also limited ongoing support for many participants, for instance to help people use the energy monitor or apply for the WHD. In addition, the charity did not help respondents raise issues with landlords, or refer issues to the local authority for follow-up, although these issues were relevant to many project participants. Another important drawback was that the project did not provide energy audits or conduct property-level energy efficiency improvements itself as the project lacked access to professional expertise and funding to provide these services. A significant barrier was that project activities were not effectively coordinated with the local authority, despite sharing information on approaches. More effective coordination with the LA could have helped the project refer vulnerable people to wider services [8]. In addition, while the BLF funding provided the opportunity for the project to work with vulnerable people, the project was only 3-years in length and received minimal technical support, limiting the scope for the charity to learn from its work and improve its activities.

A further important consideration was that environmental outcomes were minimal and were not measured. Although 25 of the 40 participants described reducing energy usage, these could be considered as quick-wins and small-scale, such as not using inefficient appliances, rather than a systematic change in how people used energy Strengers [17].

\subsection{Implications for policy and practice}

Many charities, including the charity featured in this case study, will take the initiative to help households vulnerable to fuel poverty $[9,15,16]$. The charity's household-level advice and support helped some households vulnerable to fuel poverty reduce energy costs. However, after the platform provided by BLF funding, the charity required access to longer-term reflexive funding, technical expertise and effective coordination to expand its support and increase its impacts $[3,8,9]$. Reflexive funding would provide continued financial support for effective activities. A relatively simple increase in support would include raising issues with landlords/ housing 
providers, working with more trusted intermediaries to reach more vulnerable people, providing follow-up support to households, and collecting more robust data $[8,9,38]$. Technical expertise would be required to expand support further to conduct energy audits and provide property-level energy efficiency improvements (such as improved heating systems), although many charities would need to refer households to local authorities or professional networks to provide this support [8].

In addition, the minimal environmental outcomes underline the limitations of projects which have primary aims to reduce vulnerability to fuel poverty and a separate project or funding stream maybe required to focus on these outcomes [8]. However, a longer-term project with access to networks and expertise could provide potential to consider expansion into renewable energy and more innovative approaches which could help achieve environmental goals [31].

In general, the findings indicate that while charities can help households vulnerable to fuel poverty, there is a risk that charity-led projects can be short-term, offer limited support and operate in isolation from local and UK government support. Local authorities should work closely with such projects to provide appropriate support and coordinate activities. Central Government should incentivise and support such local joint working, and the policy to roll-out smart-meters could be an opportunity to frame this support [23].

\section{Conclusion}

In conclusion, the article supports arguments from Reeves [8] and Baker et al. [9] on the need for in-person support and advice to help households vulnerable to fuel poverty. In-person support and advice can enable households to access better information, increase their confidence to manage their energy needs, and reduce energy costs. Some charities will take the initiative to help people vulnerable to fuel poverty and can operate effectively in a space between: 1) the government and energy companies; 2 ) local authorities and other social housing providers; and 3) community-level trusted intermediaries and households vulnerable to fuel poverty. However, there is a risk that charity-led projects can be short-term, have limited activities and operate in isolation. Activities to help people vulnerable to fuel poverty should be coordinated at a local level, involving local authorities, charities and other stakeholders $[8,9]$ and charities need access to reflexive funding and technical support. There is also a need for continuous research into projects that help households vulnerable to fuel poverty, the role of charities, and support from wider networks including local authorities, to provide lessons on successful approaches and challenges. 


\section{Reference list}

1. Li, X., Hou, S., Patterson, J., Perisoglou, E., lonas, M., Jenkins, H., Jones, P., Lannon, S. and Coma Bassas, E., (2019). Modelling and developing a neighbourhood low carbon system for five dwellings in the UK.

2. Poortinga, W. (2019). Health and social outcomes of housing policies to alleviate fuel poverty. In Urban Fuel Poverty (pp. 239-258). Academic Press.

3. Boardman, B., (2010). Fixing Fuel Poverty: Challenges and Solutions. Earthscan, Abingdon.

4. Walker, G., \& Day, R. (2012). Fuel poverty as injustice: Integrating distribution, recognition and procedure in the struggle for affordable warmth. Energy Policy, 49, 69-75.

5. Snell, C., Bevan, M., \& Thomson, H. (2015). Justice, fuel poverty and disabled people in England. Energy Research \& Social Science, 10, 123-132.

6. Sovacool, B. K. (2015). Fuel poverty, affordability, and energy justice in England: Policy insights from the Warm Front Program. Energy, 93, 361-371.

7. Seyfang, G., Park, J. J., \& Smith, A. (2013). A thousand flowers blooming? An examination of community energy in the UK. Energy Policy, 61, 977-989.

8. Reeves, A. (2016). Exploring local and community capacity to reduce fuel poverty: The case of home energy advice visits in the UK. Energies, 9(4), 276.

9. Baker, K. J., Mould, R., Stewart, F., Restrick, S., Melone, H., \& Atterson, B. (2019). Never try and face the journey alone: Exploring the face-to-face advocacy needs of fuel poor householders in the United Kingdom. Energy Research \& Social Science, 51, 210-219.

10. Hull City Council (2018) Joint Strategic Needs Assessment http://www.hull.gov.uk/sites/hull/files/media/2018\%20\%20Joint\%20Strategic\%20Needs\%20Assessment\%20Summary February2018.pdf

11. Buchanan, K., Staddon, S., \& van der Horst, D. (2018). Feedback in energy-demand reduction, Building Research \& Information, 46:3, 231-237,

12. Saunders, R. W., Gross, R. J. K., \& Wade, J. (2012). Can premium tariffs for micro-generation and small scale renewable heat help the fuel poor, and if so, how? Case studies of innovative finance for community energy schemes in the UK. Energy Policy, 42, 78-88.

13. Liddell, C., \& Morris, C. (2010). Fuel poverty and human health: a review of recent evidence. Energy Policy, 38(6), 2987-2997.

14. uSwitch (2019). Prepayment meters explained. https://www.uswitch.com/gaselectricity/guides/prepayment-meters/\#step4 [accessed 25 November 2019]

15. Parkhill, K. A., Shirani, F., Butler, C., Henwood, K. L., Groves, C., \& Pidgeon, N. F. (2015). 'We are a community [but] that takes a certain amount of energy': Exploring shared visions, social action, and resilience in place-based community-led energy initiatives. Environmental Science \& Policy, 53, 60-69. 
16. Lorenc, A., Pedro, L., Badesha, B., Dize, C., Fernow, I., \& Dias, L. (2013). Tackling fuel poverty through facilitating energy tariff switching: a participatory action research study in vulnerable groups. Public Health, 127(10), 894-901.

17. Strengers, Y. (2011). Negotiating everyday life: The role of energy and water consumption feedback. Journal of Consumer Culture, 11(3), 319-338.

18. Hargreaves, T., Nye, M., \& Burgess, J. (2013). Keeping energy visible? Exploring how householders interact with feedback from smart energy monitors in the longer term. Energy Policy, 52, 126-134.

19. Pullinger, M., Lovell, H., \& Webb, J. (2014). Influencing household energy practices: a critical review of UK smart metering standards and commercial feedback devices. Technology Analysis \& Strategic Management, 26(10), 1144-1162.

20. Hargreaves, T., Nye, M., \& Burgess, J. (2010). Making energy visible: A qualitative field study of how householders interact with feedback from smart energy monitors. Energy Policy, 38(10), 6111-6119.

21. Buchanan, K., Banks, N., Preston, I., \& Russo, R. (2016). The British public's perception of the UK smart metering initiative: Threats and opportunities. Energy Policy, 91, 87-97.

22. Kelly, J., \& Knottenbelt, W. (2015). The UK-DALE dataset, domestic appliance-level electricity demand and whole-house demand from five UK homes. Scientific data, 2, 150007.

23. Wilson, C., Hargreaves, T., \& Hauxwell-Baldwin, R. (2017). Benefits and risks of smart home technologies. Energy Policy, 103, 72-83.

24. Hielscher, S., \& Sovacool, B. K. (2018). Contested smart and low-carbon energy futures: media discourses of smart meters in the United Kingdom. Journal of cleaner production, 195, 978-990.

25. Starkey et al. (2017). Hull: Culture, History, Place. Liverpool University Press

26. Jonas, A. E., Wurzel, R. K., Monaghan, E., \& Osthorst, W. (2017). Climate change, the green economy and reimagining the city: the case of structurally disadvantaged European maritime port cities. DIE ERDE-Journal of the Geographical Society of Berlin, 148(4), 197-211.

27. NOMIS (2015) Official Labour Market Statistics. http://www.nomisweb.co.uk/reports/lmp/la/1946157109/printable.aspx [accessed 29 September 2016]

28. ONS (2015). The English Indices of Deprivation 2015. National Statistics Statistical Release 2015. Department for Communities and Local Government , London. https://www.gov.uk/government/uploads/system/uploads/attachment data/file/465791/Eng lish Indices of Deprivation 2015 - Statistical Release.pdf [accessed 22 April 2016]

29. National Lottery Community (2020). https://www.tnlcommunityfund.org.uk/funding/programmes/communities-living-sustainably [accessed May 2020]

30. Sovacool, B. K., Axsen, J., \& Sorrell, S. (2018). Promoting novelty, rigor, and style in energy social science: towards codes of practice for appropriate methods and research design. Energy Research \& Social Science, 45, 12-42. 
31. Gupta, R., Barnfield, L., \& Gregg, M. (2018). Exploring innovative community and household energy feedback approaches. Building Research \& Information, 46(3), 284-299.

32. Brannick, T., \& Coghlan, D. (2007). In defense of being "native": The case for insider academic research. Organizational Research Methods, 10(1), 59-74.

33. Kember, D., Ha, T. S., Lam, B. H., Lee, A., Ng, S., Yan, L., \& Yum, J. C. (1997). The diverse role of the critical friend in supporting educational action research projects. Educational Action Research, 5(3), 463-481.

34. Tornaghi, C., \& Van Dyck, B. (2015). Research-informed gardening activism: steering the public food and land agenda. Local Environment, 20(10), 1247-1264.

35. Department for Business, Energy and Industrial Strategy (2018) https://www.gov.uk/government/collections/fuel-poverty-statistics [accessed 10 May 2019]

36. Simcock, N., Walker, G., \& Day, R. (2016). Fuel poverty in the UK: beyond heating. People, Place and Policy, 10(1), 25-41.

37. Hargreaves, T. (2018). Beyond energy feedback. Building Research \& Information, 46(3), 332342.

38. Stephenson, J., Barton, B., Carrington, G., Gnoth, D., Lawson, R., \& Thorsnes, P. (2010). Energy cultures: A framework for understanding energy behaviours. Energy Policy, 38(10), 6120-6129. 